\title{
Primary care social work practice with older adult veterans during the Covid-19 pandemic: An application of Ecological Systems Theory
}

\author{
Lashawn Smith ${ }^{1,2}$ \\ ${ }^{1}$ U.S. Department of Veteran Affairs \\ ${ }^{2}$ Graduate School of Social Services, Fordham University, New York, NY, USA
}

Received 22 September 2020

Accepted for publication 29 November 2020

Published 18 December 2020

\begin{abstract}
In March 2020, the state of New York became the American epicenter of the Covid-19 pandemic with the most vulnerable of populations including older adults being affected. Coronavirus disease (Covid-19) is an infectious disease caused by a newly discovered corona virus resulting in mild to moderate respiratory illness (World Health Organization, 2020). As of September 2020, there have been over 6 million Covid-19 cases and over 200,000 deaths in the United States (Center for Disease Control, 2020a). Additionally, as of September 2020 The U.S. Department of Veterans Affairs has diagnosed over 56,000 veterans with Covid-19 (U.S. Department of Veterans Affairs, 2020b). While utilizing an ecological systems theoretical framework and applying its tenets, this reflective article will explore how, as a primary care social worker in the Veterans Health Administration in New York City, I worked through the Covid-19 pandemic to effectively provide social work services and case management to older adult veterans.
\end{abstract}

Keywords: social work practice, veterans, Covid-19, older adults, primary care

\section{Primary care social work}

The Veterans Health Administration is America's largest integrated health care system serving 9 million veterans each year and is also the largest employer of licensed social workers nationwide (Veterans Health Administration, 2020). Primary care social workers are tasked with a myriad of duties to address social determinants of health including housing, economics, access to care, psychological status, functional status and social support deficits experienced by veterans, their families, and caregivers. Studies have shown that having social workers in primary care settings reduce emergency room visits as well as improve patient health and mental health outcomes among community dwelling older adults (Cornell et al., 2020; Firth et al., 2003; Lorig et al., 2001).

\section{Theoretical framework}

Theory is an essential ingredient in practice that guides the way in which social workers view and approach individuals
(Teater, 2010). There is a paucity of research on primary care social work service delivery during pandemics in the United States and those that are published have utilized the National Association of Social Workers (NASW) Code of Ethics as their guiding framework rather than a theoretical framework (Bright, 2020; Miller and Lee, 2020).

One study that utilized a theoretical framework was conducted by Rowland (2007) amongst hospital social workers in Singapore during the 2007 SARS pandemic. The study examined the range of interventions adopted by medical social workers and the theoretical orientations underpinning them. The study revealed that although social workers were guided by social work values, many had not utilized theoretical frameworks in relation to unprecedented types of emergencies.

Ecological Systems Theory posits that a person's development is affected by everything in their environment and that the environment is positioned into five different interconnecting structures and systems (Bronfenbrenner, 
1979). These systems are referred to as the microsystem, mesosystem, exosystem, macrosystem, and chronosystem. The client's ecosystem is composed of numerous overlapping systems including the family, the workplace, and the community, as well as other critical subsystems unique to each client (Pardeck, 1988). Inferring that these systems play a vital and impactful role in development underscores this theoretical premise. The ecological systems theory makes a substantial contribution to the understanding of an individual's role and behavior in relation to the context surrounding them on different levels.

\subsection{Microsystem - advance care planning}

The microsystem refers to the activities and relationships an individual interacts with on a day to day basis (Neber, 2018). One of these interactions within the primary care setting that older adult veterans are encouraged to utilize is advance care planning with social workers. Advance care planning is defined as a process of clarifying one's values and health care choices for future use when they are no longer able to make decisions for themselves (U.S. Department of Veterans Affairs, 2020c). According to the Center for Disease Control (2020b) 8 out of 10 deaths reported from Covid-19 have been amongst adults aged 65 years and older making the need for advance care planning more critical. Aspects of advance care planning include a myriad of areas such as advance directives, do not resuscitate orders and goals of care conversations. The Veterans Health Administration handbook policy 1004.03 defines goals of care conversations as a discussion between a healthcare practitioner and a patient or surrogate for the purpose of determining the patient's values, goals, preferences for care. Since many hospitals were at maximum capacity with patients and halted all visitation, advance care planning was a critical part of my role as a primary care social worker with older adult veterans.

\subsection{Mesosystem - caregiver support}

The mesosystem refers to the interactions between the microsystems that the person experiences daily (Neber, 2018). Regularly providing and supporting open communication between primary care social workers and caregivers is an illustrative example of how incorporating the mesosystem into practice supported the wellbeing of older adult veterans during the Covid-19 pandemic. There are over 40 million unpaid caregivers of adults aged 65 and over in the United States and within that group 9 out of 10 are providing care for an aging relative (Stepler, 2015). In my role as a primary care social worker, I noticed that several older adult veterans were in predicaments where their caregivers made the difficult choice not to visit them due to the high risk and susceptibility of
Covid-19. As a result, there was an influx in calls from caregivers and family members. Many of the calls consisted of inquiries about available resources and services that could be put into place to ease the void that their absence from caregiving had created. In my experience, working with family and caregiver systems and being easily accessible was an integral part of case management service delivery during the Covid-19 pandemic. Additionally, having a centralized program in place specifically for caregivers to access via phone was helpful as it ensured an additional point of contact that caregivers could access for assistance. For example, the Veterans Health Administration national caregiver support line was an easily accessible hotline staffed by licensed professionals and served as a primary resource and referral center to assist caregivers, veterans, and others seeking caregiver information.

\subsection{Exosystem - coordination of services}

The exosystem refers to the systems that are external to an individual that influences their microsystems and that of which they have no control over (Neber, 2018). During the Covid-19 pandemic, non-essential businesses and services were ordered to shut-down by the state government. As a result of the shutdown, there was an increase in the need for referrals for in-home services for older adult veterans.

With many primary care clinics activating temporary closures or reduction in visits to slow the spread of Covid-19, many older adult veterans cautiously opted to remain at home. In fact, patients with cancer and heart disease were delaying or forgoing critical procedures with some even being afraid to set foot in an emergency room or doctor's office (Hafner, 2020). This common phenomenon created an increase in need for coordination of services and referrals. Coordination of services and referrals included referrals to the VA Homemaker/HHA program for veterans needing assistance with activities of daily living and visiting nurse services for those veterans needing skilled nursing care at home. In many cases, these service referrals, all of which required interdisciplinary collaboration and assessments, were quickly expedited, and put into place typically within 72 hours. Ensuring that older adult veterans can continue to remain safely at home will require social workers to continue to work collaboratively with an interdisciplinary team to expeditiously put in-home support services in place.

\subsection{Macrosystem - virtual care}

The macrosystem consists of the cultural and societal structures that influence the microsystem, mesosystem, and exosystem (Neber, 2018). The Covid-19 pandemic prompted many primary care clinics to temporarily close or substantially 
reduce face to face visits. As a result, healthcare providers expanded utilization of virtual care platforms to provide care to patients in lieu of the traditional face to face visits. In March 2020, the Centers for Medicaid \& Medicare Services removed the requirement for patients to travel to an "originating site" to receive care remotely and the Department of Health and Human Services waived penalties for the use of non-HIPAA compliant communication tools including popular applications like FaceTime or Zoom (Centers for Medicare and Medicaid Services, 2020).

According to the National Association of Social Workers Standards for Technology in Social Work Practice (NASW, 2017) standard 2.01 (i.e. ethical use of technology to deliver social work services when providing services to individuals, families, or groups using technology), social workers should follow the National Association of Social Workers code of ethics just as one would when providing services to clients in person. .

Veterans Video Connect (VVC) is a Veterans Health Administration electronic application platform that enabled veterans to meet with their healthcare providers virtually. The author worked with older adult veterans to decrease the digital divide by linking them to programs and services that provided technology devices such as tablets and smartphones to access their healthcare. It seems that ensuring that older adult veterans have access to technology-based platforms, will be a critical requisite in the structural and societal landscape of social work service delivery and healthcare accessibility as the shift to virtual platforms continues to expand.

\subsection{Chronosystem - long term planning}

The chronosystem represents the socio-historical context and environmental events and transitions that occur for the individual and within which the various systems operate (Neber, 2018). In the United States, the average life expectancy at birth in 2017 was 78.6 years (Arias and $\mathrm{Xu}$, 2019). This lends support to the notion that many people are living longer and will likely require higher levels of care than can be provided in one's own home or natural dwelling. Historically, the United States has had the most comprehensive system of assistance for veterans compared to other nations dating back to the Civil War when veterans nursing homes were established (U.S. Department of Veterans Affairs, 2020a).

Primary care social work practice with older adult veterans has traditionally included long term planning in the trajectory of services provided. Primary care social workers routinely provide psychoeducation to clients and families on the longterm placement process including transitioning into assisted living facilities and nursing homes.
Making the decision of whether to transition a loved one into a nursing home can be met with feelings of ambivalence to those in the decision-making role. The Covid-19 pandemic has caused the imposition of visitor restrictions with many nursing homes temporarily halting all visitation and this within itself has contributed to greater feelings of ambivalence. Historically, nursing home placement has been shown to be an agonizing event that may cause reciprocal emotional suffering for the older adult and their family members along with the psychological burdens of guilt, regret, and loss for the family (Funk et al., 2010; Wilkes et. al., 2008).

Primary care social workers will need to accelerate their level of expertise with best practices in relation to long term planning with older adults as doing so will contribute to the successful transition, particularly during a pandemic, into a nursing home.

\section{Conclusion}

The value of theory application in social work practice is plentiful in several aspects. Utilizing theory in social work practice can aid in explaining client situations and predicting their behaviors; provide social workers with a perspective to conceptualize and address client problems with appropriate interventions, and ultimately identify knowledge gaps within practice (Gentle-Genitty et. al., 2014; Gilson and DePoy, 2002)

The Covid-19 pandemic has reshaped social work service delivery in many settings, and it is critical that theoretical frameworks are incorporated as a guiding framework during practice with older adult veterans. Providing access to advance care planning, caregiver support, coordination of services and referrals, virtual care, and long-term planning should be a hallmark standard of social work practice to ensure that older adults veterans can remain safely at home in the community during a pandemic that places them at highest risk for impact and loss of life.

\section{References}

Arias, E. and Xu, J. (2019) United States life tables, 2017. National Vital Statistics Reports. Hyattsville, MD: National Center for Health Statistics.

Bright, C. (2020) Social Work in the Age of a Global Pandemic, Social Work Research, (44)2, pp. 83-86.

Bronfenbrenner, U. (1979) The ecology of human development. Cambridge: Harvard University Press.

Center for Disease Control (2020a) Corona Virus Disease. Available at: https://www.cdc.gov/coronavirus/2019ncov/cases-updates/cases-in-us.html (Accessed: 21 September 2020).

Center for Disease Control and Prevention (2020b) Older adults. CDC/Coronavirus Disease 2019 (COVID-19). 
Available at: https://www.cdc.gov/coronavirus/2019ncov/need-extra-precautions/older-adults.html (Accessed: 21 September 2020).

Centers for Medicare \& Medicaid Services (2020) Medicare Telemedicine Health Care Provider Fact Sheet. Available at: https://www.cms.gov/newsroom/fact-sheets/medicaretelemedicine-health-care-provider-fact-sheet (Accessed: 21 September 2020).

Cornell, P.Y., Halladay, C.W., Ader, J., Halaszynski, J., Hogue, M., McClain, C.E. and Rudolph, J.L. (2020) Embedding social workers in Veterans Health Administration Primary Care Teams reduces emergency department visits: An assessment of the Veterans Health Administration program to add social workers to rural primary care teams. Health Affairs, 39(4), pp. 603-612.

Firth, M., Dyer, M., Marsden, H. and Savage, D. (2003) Developing a social perspective in mental health services in primary care. Journal of Interprofessional Care, 17(3), pp. 251-261.

Funk, L.M., Stajduhar, K., Toye, C., Aoun, S., Grande, G.E. and Todd, C.J. (2010) Home-based family caregiving at the end of life: A comprehensive review of published qualitative research (1998-2008). Palliative Medicine, 24, pp. 594-606.

Gentle-Genitty, C., Chen, H., Karikari, I. and Barnett, C. (2014) Social work theory and application to practice: The students' perspectives. Available at: SocialWorkTheoryandApplicationtoPracticeTheStudentsPerspectives (1).pdf

(Accessed: 2 December 2020).

Gilson, S.F. and DePoy, E. (2002) Theoretical approaches to disability content in social work education. Journal of Social Work Education, 38(1), pp. 153-165.

Hafner, K. (2020, May 25) Fear of covid-19 leads other patients to decline in critical treatment. The New York Times. Available at:

https://www.nytimes/com/2020/0/5/25/health/coronaviruscancer-heart- treatment.html (Accessed: 17 October 2020).

Lorig, K.R., Sobel, D.S., Ritter, P.L., Laurent, D. and Hobbs, M. (2001) Effect of a self-management program on patients with chronic disease. Effective Clinical Practice, 4(6), pp. 256-62.

Neber, E. (2018) Nontraditional students' transition to college through the lens of bronfenbrenner's ecological theory, schlossberg's transition theory and gender schema theory, pp.11. Available at: NeberE1218.pdf (montana.edu) (Accessed: 17 October 2020).

Miller, V.J. and Lee, H. (2020) Social Work Values in Action during COVID-19. Journal of Gerontological Social Work, published online,

doi: https://doi.org/10.1080/01634372.2020.1769792

NASW, ASWB, CSWE and CSWA Standards for Technology in Social Work Practice (2017). Available at: https://www.socialworkers.org/includes/newincludes/home page/PRA-BRO-

33617.TechStandards FINAL POSTING.pdf (Accessed: 21 September 2020).
Pardeck, J.T. (1988) An Ecological Approach for Social Work Practice. The Journal of Sociology \& Social Welfare, 15(2), pp. 136-137.

Rowlands, A. (2007) Medical Social Work Practice and SARS in Singapore. Social Work in Health Care, 45(3), pp. 57-83.

Stepler, R. (2015) Five facts about Family Caregivers Available at: https://www.pewresearch.org/facttank/2015/11/18/5-facts-about- family-caregivers/ (Accessed: 21 September 2020).

Teater, B. (2010) An introduction to applying social work theories and methods. Available at: file:///C:/Users/Owner/Downloads/Chapter1_new.pdf (Accessed: 17 October 2020).

U.S. Department of Veterans Affairs (2020a) About VA VA History: Available at: https://www.va.gov/about va/vahistory.asp Accessed: 17 October 2020).

U.S. Department of Veterans Affairs (2020b) Covid-19 Pandemic Response: Weekly Report. Available at: https://www.va.gov/health/docs/VA_COVID_Response.p df (Accessed: 21 September 2020).

U.S. Department of Veterans Affairs (2020c). Geriatrics and Extended Care - Advance Care Planning. Available at: https://www.va.gov/geriatrics/pages/advance_care_planni ng topics.asp (Accessed: 21 September 2020).

Veterans Health Administration (2020) Providing Health Care for Veterans. Available at: https://www.va.gov/health/ (Accessed: 17 October 2020).

Wilkes, L., Jackson, D. and Vallido, T. (2008) Placing a relative into a nursing home: Family members' experiences after the move. A review of the literature. Geriaction, 26(1), pp. 24-29.

World Health Organization. 2020. Coronavirus. Available at: https://www.who.int/westernpacific/healthtopics/coronaviurs (Accessed: 21 September 2020). 